\title{
LOS NUEVOS MEDIOS DE COMUNICACIÓN ESTRATÉGICA HACIA EL CONSUMIDOR
}

\section{THE NEW MEDIA AND COMMUNICATION STRATEGY TOWARDS THE CONSUMER}

\section{AUTOR}

\section{Javier Sierra Sánchez}

Universidad San J orge de Zaragoza. Zaragoza (España)

jsierra@usj.es

\section{RESUMEN}

Dentro de una economía de servicios, el ambient marketing representa para muchos profesionales de agencia y directivos, un formato más, pero rupturista y sugerente de un tipo de comunicación que refuerza misteriosamente (intuición más que deducción), la imagen de marca y las ventas de los productos de las grandes empresas. De momento, la abstinencia práctica de las PyMES resulta mayor. Es precisamente, el componente de incertidumbre suscitado por ese misterio, similar en parte al del patrocinio y el mecenazgo, el que dentro del ámbito académico, tampoco queda resuelto ontológicamente. Resultan tenues y "recetaristas" las aportaciones literarias provenientes de la gestión del marketing relacional, y simplemente inexistentes las de aquellos investigadores adscritos al abanico conceptual que aflora de la teoría de la comunicación y de la psicología social. Este trabajo, precisamente, lo que pretende es reconstruir teóricamente un modelo para este fenómeno, hasta establecer unas mínimas bases comunicacionales o "en relación" -puesto que adscribe al ambient marketing (nueva psicología del consumo) la categoría intrínseca de agente dinámico con múltiples públicos dispersos y no estático con un solo 
público concentrado-, siendo así capaz de revisar fraccionadamente la huella teleológica secuencial de la acción humana en dicho proceso.

\section{PALABRAS CLAVE}

Ambient marketing - Teoría de la comunicación - Disonancia cognoscitiva - Públicos dispersos - Modelo teórico.

\section{ABSTRACT}

Within a service economy, many agency professionals and directors view ambient marketing as just another format, while at the same time seeing it as an innovative and tempting via of communication, which mysteriously reinforces (more through intuition than deduction) the brand image and product sales of large companies. At present, the practical absence of SMEs in this area is apparent and this is precisely the element of uncertainty arising from this mystery, similar in a way to that of sponsorship and patronage, which in an academic context has not been ontologically resolved either. The literary contributions from relational marketing management, have turned out to be weak and predictable and completely absent from those researchers ascribing to the conceptual range deriving from communication theory and social psychology. What this paper aims to do is theoretically reconstruct a model for this phenomenon with the objective of establishing a minimum communicational or related base - as it ascribes to ambient marketing (consumer psychology) the intrinsic category of a dynamic agent with a multiple, dispersed and active public which is not wholly concentrated in one type of public - in this way, it will be able to fractionally review the sequential teleological traces of human action in this process. 


\section{KEY WORDS}

Ambient marketing - Communication theory - Cognitive dissonance - Dispersed public

- Theoretical model

\section{ÍNDICE}

1.- Introducción.

2.- Below The Line: Ambient Marketing

3.- Ambient Marketing: Fenómeno Comunicacional

4.- Ambient Marketing: Para Captar La Atención

5.- Otros aspectos a considerar

6.- Conclusiones

7.- Bibliografía

\section{1.- Introducción}

Como ciudadanos y consumidores a muchos nos resulta conocido el término de ambient marketing, pero sin embargo, como científicos no resulta fácil encontrar el rigor académico en el concepto. La raíz epistemológica de este fenómeno publicitario y relacional no está clara. En este artículo vamos a formular una aproximación (desde la teoría de la comunicación, la psicología social y el marketing) a esta realidad para plantear un modelo teórico. 


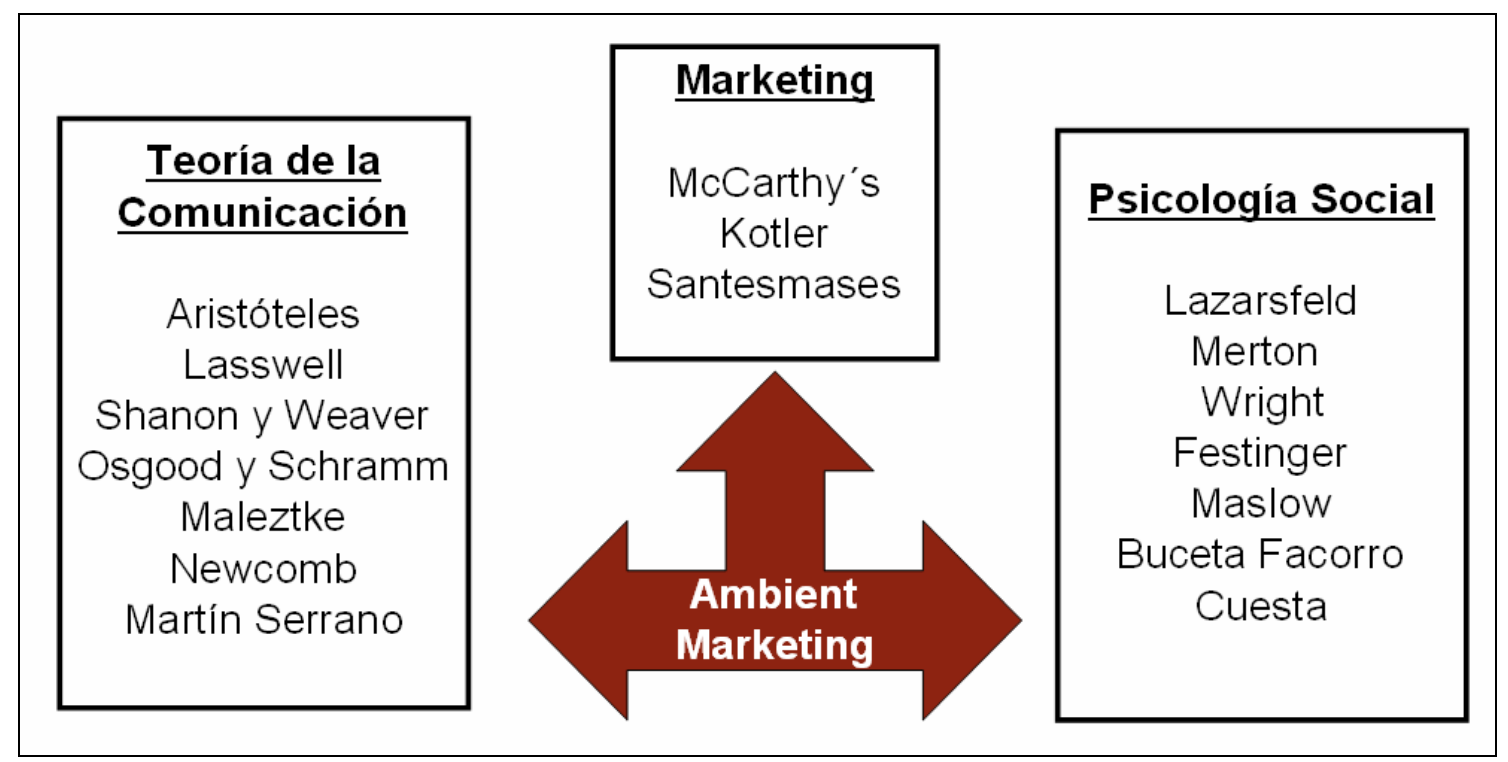

Figura 1: Aproximación multidisciplinar al ambient marketing

Los anunciantes observan que los medios de comunicación están saturados de información publicitaria. En algunos casos, como el de la televisión, España rebasa los límites que establece la Unión Europea sobre publicidad televisiva ${ }^{1}$. Los anunciantes ante la saturación y el alto coste que supone invertir en medios convencionales; están apostando cada vez más por medios no convencionales. De esta situación nos da cuenta Madinaveitia (2005:1) cuando indica: "hoy en día un solo bloque de publicidad en televisión puede llegar a incluir más de setenta anuncios $y$, por otra parte hemos invadido con publicidad el propio contenido de los programas". En el mismo texto, unas líneas después, señala: "¿ES ahora la publicidad menos eficaz?, ¿tiene menos memoria el consumidor? No, simplemente hemos aumentado nuestro grado de exigencia y se lo estamos poniendo mucho más difícil a esa memoria, cada vez más entrenado para recordar lo que le interesa...pero también para olvidar todo aquello que considera superfluo. Ahora recordamos mucho más en términos absolutos, pero un porcentaje mucho menor del total de los mensajes que recibimos".

A este respecto destaca la organización de actos públicos que se concretan en un determinado evento. Conviene diferenciar los conceptos de acto y evento. El acto es

\footnotetext{
${ }^{1}$ Así lo refleja la noticia del diario El País el día 07/03/2007 en la pág. 39.
} 
un concepto más amplio que estaría referido a la naturaleza de la acción (público, privado, oficial, empresarial, etc) y el evento (acontecimiento) sería la forma en la que se concreta ese acto. Éstos suponen una nueva forma de comunicación que utilizan las organizaciones como estrategia de diferenciación en los sectores más copados. Es en este tipo de contextos comunicativos, cuando el ambient marketing se configura como una solución de comunicación alternativa ante la falta de interés que generan en el receptor los espacios (soportes y formatos) de publicidad convencional.

Un público menos impresionable demanda fórmulas más agresivas a la sombra de la sensación de la contaminación visual que castiga muchos intentos de hacer publicidad exterior; y a la de un público que cada vez se sorprende menos con los mensajes publicitados que recibe a través de los medios convencionales. Se ha impuesto la necesidad de buscar nuevos y mejores medios para llegar al receptor.

Este tipo de evento publicitario y relacional se caracteriza por ser original y novedoso fundamentalmente. Independientemente de su naturaleza poseen un fin: establecer con el consumidor y stakeholders una comunicación persuasiva eficaz ${ }^{2}$.

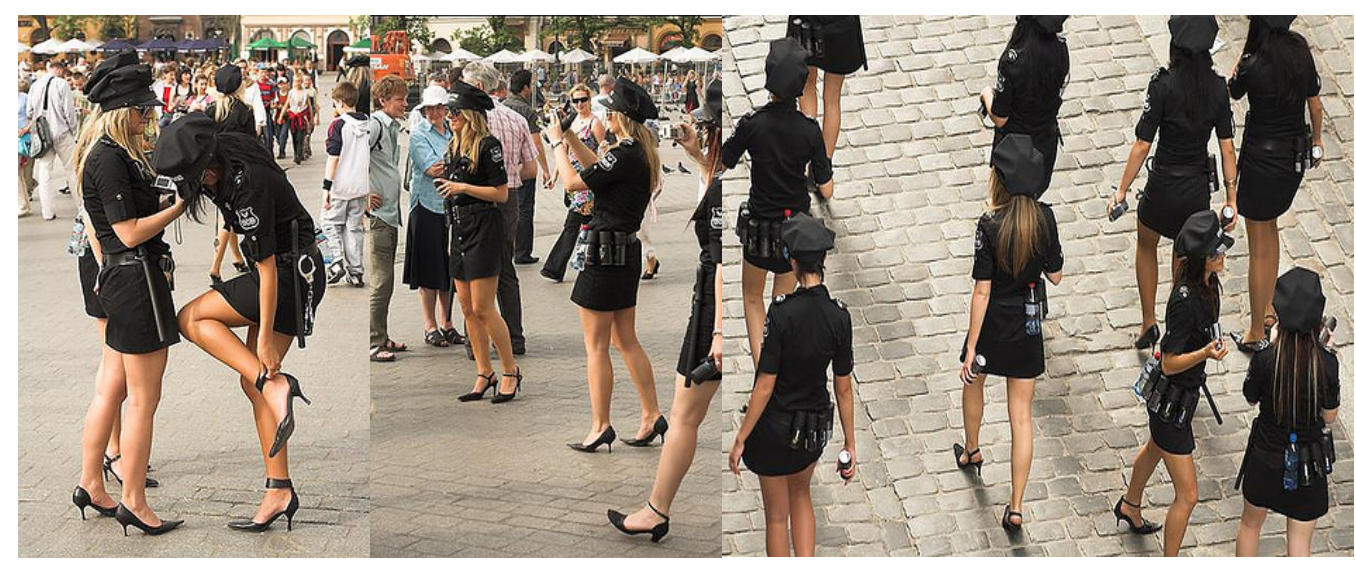

Figura 2: Acción de ambient marketing desarrollado por la marca de desodorante AXE

\footnotetext{
${ }^{2}$ Para nosotros la eficacia pasa siempre por aumentar el valor de la marca, como intangible dentro de la compañía y como razón de intercambio de los consumidores y demás stakeholders y como fuente de la ventaja competitiva sostenible a largo plazo.
} 


\section{2.- Below The Line: Ambient Marketing}

El marketing en esta época postmoderna está experimentando una continua renovación de formas, estilos y estrategias de comunicación para tratar de impactar a un huidizo público consumidor. Fruto de esos cambios nace el tipo de marketing que es objeto de estudio en este artículo.

Este tipo de acciones de marketing de ambiente $y / 0$ de entorno nacen dentro del contexto de la época postmoderna. En esta etapa, las teorías del marketing empiezan a cuestionar el eje básico del marketing basado en las cuatro $\mathrm{P}^{\prime} \mathrm{s}^{3}$. Sin embargo el marketing postmoderno empieza a cuestionar determinados aspectos:

- que el consumidor sea maleable y pasivo.

- las omnipotentes herramientas tradicionales de comunicación.

- la efectividad de los medios de comunicación masiva.

- el poder persuasivo de la publicidad.

La etapa postmoderna ha dado lugar a unas nuevas formas y denominaciones de marketing en función de los objetivos y de las acciones que persigue.

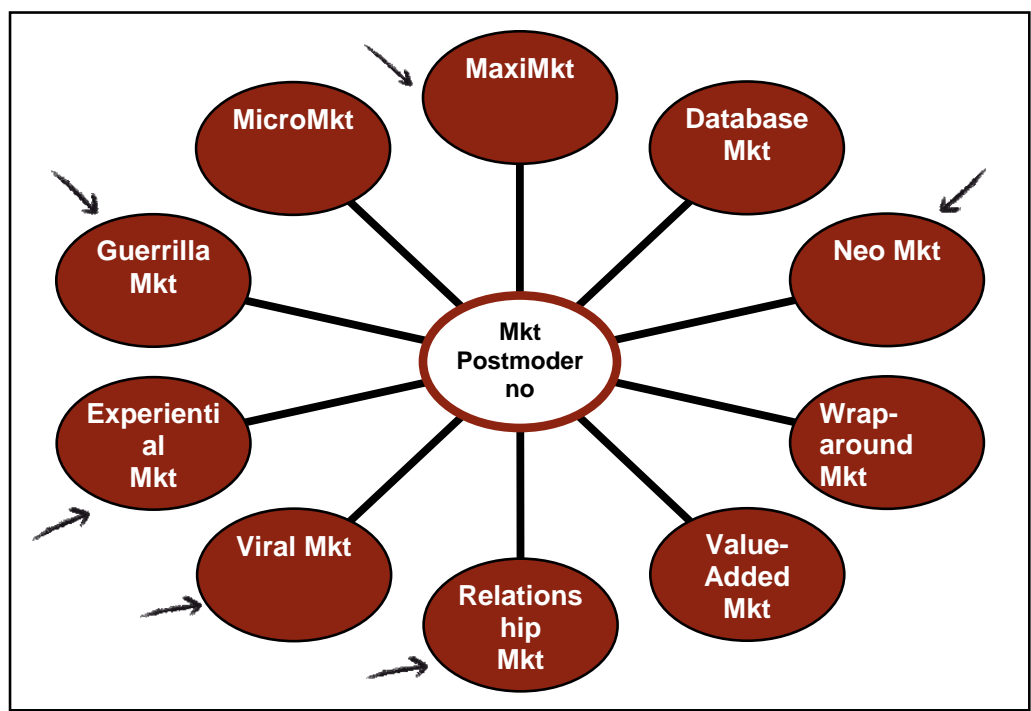

Figura 3: Nuevas formas de marketing postmoderno

\footnotetext{
${ }^{3}$ Cfr. KOTLER.P. (2003): Fundamentos del marketing, Pearson Educación. México.
} 
Así encontramos denominaciones como: maximarketing ${ }^{4}$, micromarketing ${ }^{5}$, database marketing ${ }^{6}$, neomarketing ${ }^{7}$, wrap-around marketing ${ }^{8}$, value-added marketing ${ }^{9}$, relationship marketing, viral marketing, marketing de guerrilla y experiential marketing. Todas estas denominaciones y tendencias del marketing posmoderno se presentan como alternativas del marketing tradicional. Estas acciones de comunicación comparten algunos objetivos en común:

- hacen hincapié en tratar al consumidor como un individuo.

- intentar mantener la fidelidad de sus actuales consumidores.

- adaptarse al entorno económico, político y social.

- aprovechar todos los canales de comunicación posibles para contactar con el público objetivo.

Bajo la denominación de medios no convencionales se encuentran comprendidos aquellos medios publicitarios que de forma habitual son agrupados bajo la expresión "below the line". La organización de eventos publicitarios y relacionales (ambient marketing) están dentro de este tipo de medios no convencionales.

Dentro de los medios no convencionales, cabe preguntarse, ¿dentro de qué medios publicitarios no convencionales podemos realizar eventos (acciones) de ambient marketing? En todos aquellos medios no convencionales que exigen al receptor una determinada acción; a saber: animación en punto de venta, ferias y exposiciones y patrocinio, mecenazgo y marketing social.

\footnotetext{
${ }^{4}$ Consiste en un modelo de contacto directo e implicación de la marca con el consumidor con el objetivo de aumentar las ventas y la lealtad de la marca.

${ }^{5}$ Proceso de segmentación extrema del mercado.

${ }^{6}$ Hace referencia a la capacidad de los profesionales del marketing directo de hablar con un numeroso público objetivo como si fueran individuos.

${ }^{7}$ Afirma que ha nacido un nuevo marketing que no sólo se propone subir el volumen sino más bien aprovechar los vehículos de comunicación de una manera más acertada y efectiva.

${ }^{8}$ Una acción que propone que en lugar de pretender conseguir nuevos consumidores para las marcas, se debería destinar mayores esfuerzos en mantenerlos.

${ }^{9}$ En lugar de ofrecer más y nuevos productos a los consumidores se debe mejorar y potenciar los ya existentes.
} 


\begin{tabular}{|c|c|c|c|c|c|c|}
\hline \multirow{2}{*}{$\begin{array}{l}\text { MEDIOS NO } \\
\text { CONVENCIONALES }\end{array}$} & \multicolumn{3}{|c|}{$\%$ INC. } & \multirow[b]{2}{*}{2005} & \multirow[b]{2}{*}{2004} & \multirow[b]{2}{*}{2003} \\
\hline & 2007 & $07 / 06$ & 2006 & & & \\
\hline Maliling Personalizado & $1.939,5$ & 4,0 & $1.864,9$ & $1.776,1$ & $1.734,5$ & $1.700,5$ \\
\hline Buzoneo/Folletos & 823,6 & 8,8 & 757,0 & 729,2 & 744,1 & 752,4 \\
\hline Marketing Telefónico & $1.058,6$ & 9,4 & 967,7 & 897,6 & 832,0 & 763,6 \\
\hline Regalos Publicitarios & 388,0 & 3,8 & 373,8 & 357,1 & 365,2 & 361,6 \\
\hline P.L.V., Merchandising, Señalización y Rótulos & $1.538,0$ & 20,6 & $1.275,3$ & $1.225,9$ & $1.086,1$ & $1.048,1$ \\
\hline Ferias y Exposiciones & 200,7 & 14,9 & 174,7 & 150,4 & 142,1 & 130,8 \\
\hline Actos de Patrocinio, Mecenazgo y Marketing Social y & S.C. 495,1 & 12,8 & 438,9 & 401,5 & 348,4 & 324,7 \\
\hline Actos de Patrocinio Deportivo & 623,4 & 11,2 & 560,6 & 493,0 & 470,5 & 442,6 \\
\hline Publicaciones de Empresa, Boletines, Memorias & 53,3 & $-11,5$ & 60,3 & 59,4 & 56,6 & 56,7 \\
\hline Anuarios, Guías y Directorios & 638,6 & 5,7 & 604,2 & 589,0 & 553,7 & 511,3 \\
\hline Catálogos & 193,7 & $-7,3$ & 209,0 & 241,5 & 225,2 & 217,7 \\
\hline Juegos Promodionales & 55,9 & 15,1 & 48,6 & 38,2 & 36,2 & 39,1 \\
\hline Tarjetas de Fidalización & 45,9 & 14,9 & 40,0 & 34,8 & 32,4 & 32,6 \\
\hline Animación en Punto de Venta & 69,9 & 6,2 & 65,8 & 71,0 & 66,7 & 62,7 \\
\hline SUBTOTAL MEDIOS NO CONVENCIONALES & $8.124,4$ & 9,2 & $7.440,7$ & $7.064,8$ & $6.693,6$ & $6.444,4$ \\
\hline
\end{tabular}

Figura 4: Cifras de la inversión en los medios no convencionales

Vamos a tratar de elaborar una definición que explique qué es el ambient marketing. Lo definimos como una estrategia de comunicación publicitaria basada en la creación de eventos que emplean las organizaciones para promocionar productos y servicios a través de medios no convencionales (below the line) en emplazamientos concurridos de personas. Este tipo de acciones suponen mayor energía y trabajo de la organización anunciante pero un considerable ahorro de costes (no siempre y necesariamente). Por lo tanto la publicidad no convencional o alternativa trata, como señala Cabrera ${ }^{10}$, de formas de comunicación que estén cerca de:

- la experiencia

- la compra

- del target

- en el territorio de la marca

\footnotetext{
${ }^{10}$ Cabrera, Álvaro. (2006) Qué estamos midiendo cuando medimos eficacia. Como abordar la medición de la comunicación no convencional. XI Seminario SEDEMO-aea: Eficacia de la comunicación Publicitaria. Barcelona 2 y 3 de Junio.
} 


\section{3.- Ambient Marketing: Fenómeno Comunicacional}

En el actual contexto sociocultural, podemos aseverar que la comunicación publicitaria, en tanto forma de producción industrializada de la realidad, se ha convertido en la base del intercambio transmisivo entre el mundo de lo social y el ámbito comercial. La publicidad se erige, por tanto, como una herramienta para la seducción de los consumidores, encauzando la eficacia de su impacto a través de una "acción comunicativa" determinada, a su vez, por una capacidad de atracción, asimilación y repercusión desde el punto de vista psicológico. Una relación con el destinatario afianzada, pues, a través del intercambio relacional entre el entramado cognitivo, el ámbito estético y el propio aparataje persuasivo, reflexiona San Nicolás Romera (2003:165).

Los anunciantes realizan este tipo de publicidad no convencional para conectar con los públicos de una forma efectiva y más seductora. Si como decíamos anteriormente, cuando se realiza un acto se comunica, las empresas organizan este tipo de eventos con un fin. Por lo tanto, cuando organizamos un evento, se activa un modelo de comunicación persuasiva. De Fleur Ball-Rokeach (1993) indica que existen cuatro posibles comportamientos que pueden ser el objeto de cualquier tipo de comunicación persuasiva: el voto, la donación, la compra y la obediencia.

En las siguientes líneas trataremos de elaborar de forma aproximada, desde el enfoque de Teoría de la comunicación y la información, un modelo de comunicación que activan las acciones de ambient marketing. El modelo es una representación de objetos o componentes, acontecimientos, procesos o sistemas, y que puede ser utilizada de una forma analítica. Nos sirven para describir y explicar la naturaleza de este fenómeno comunicacional y de relación. 


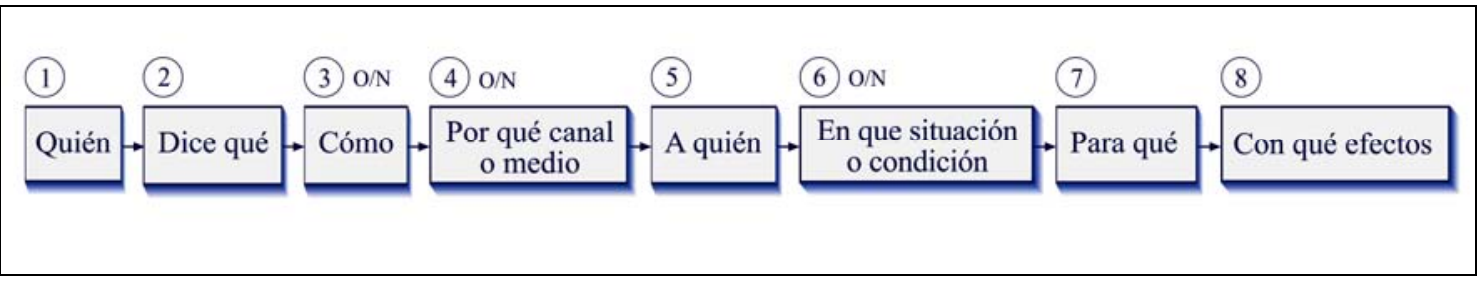

Figura 5: Modelo lineal de comunicación publicitaria aplicado a los eventos de ambient marketing

A continuación paso a explicar cada una de las fases:

1. Quien: sería el emisor de la entidad, organización y marca que se promociona a través de una acción de ambient marketing.

2. Dice qué: estaríamos hablando del mensaje que queremos dar con la organización de ese acto 0 evento.

3. Cómo: hace referencia a la forma creativa sobre la que vamos a plantear la acción de ambient marketing.

4. Por qué canal o medio: si las acciones de ambient marketing, son un tipo de estrategia en la que el receptor entra en contacto directo con la marca, estamos ante un tipo de comunicación no mediada. Ese contacto directo permite crear ambientes creativos/originales de comunicación interpersonal masivos no mediados.

5. A quién: hace referencia al público al que queremos invitar o hacer partícipe de un acto 0 acción de ambient marketing.

6. En qué situación o condición: este punto está relacionado con las circunstancias espacio temporales (contexto) en el que se encuentran emisor y receptor en el momento de llevar a cabo una acción de ambient marketing. Todas las circunstancias que rodean la situación comunicativa condicionan la capacidad persuasiva de la acción de ambient marketing.

7. Para qué: este apartado lo afrontamos desde dos puntos de vista:

7.1 Objetivos de comunicación del emisor: vender, promocionar productos y concienciar de determinadas patrones de conducta.

7.2 Objetivos de comunicación que se quieren causar en el receptor: Pueden existir dos tipos de objetivos que queramos causar en el receptor: persuadir e informar. 
8. Con qué efectos: en definitiva, qué resultados queremos provocar en el receptor. Entendiendo receptor, no solo la persona física que asiste al acto sino también en el lugar en el que se desarrolla este tipo de eventos.

En los puntos 3,4 y 6 observamos que aparecen las iniciales $(\mathrm{O} / \mathrm{N})$ referidas a originalidad y novedad. Sobre estos tres apartados gravita la acción creativa de la acción de ambient marketing. Cuanto mayor sea la originalidad y novedad de la acción de ambient marketing mayor será la capacidad para llamar la atención de los receptores que se exponen.

Pero las acciones de comunicación de ambient marketing se desarrollan a través de un tipo de comunicación no mediada que generan un modelo de comunicación circular de doble flujo.

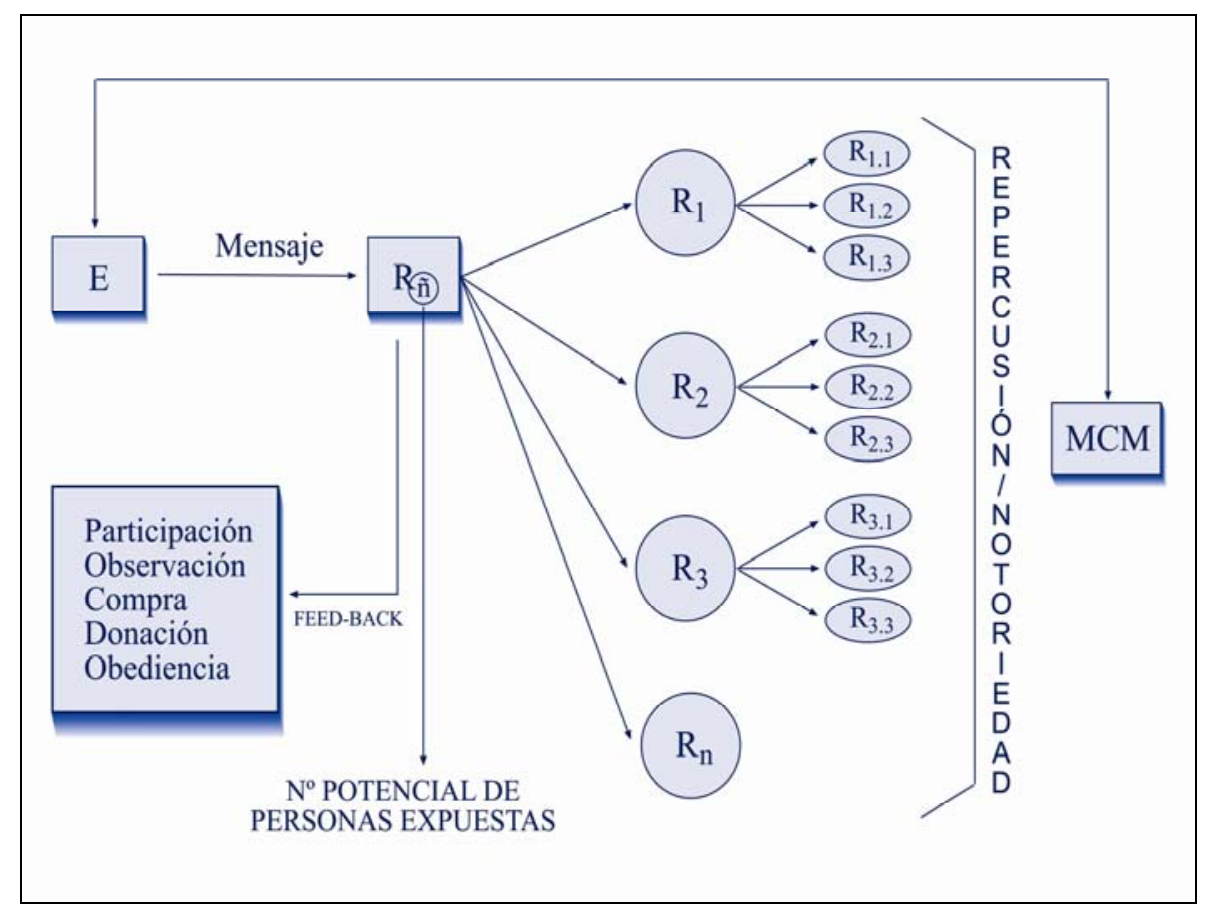

Figura 6: Modelo circular de comunicación publicitaria aplicado a los eventos de ambient marketing

Como observamos en la figura, además de un proceso de comunicación comercial persuasiva, activamos un proceso de relación interpersonal entre los asistentes al 
acto y entre éstos y sus entornos de socialización. Los públicos entran en contacto (experiencia) con el emisor a través de la participación del receptor en el evento.

El emisor (anunciante) envía un mensaje a los receptores concentrados en el lugar en el que se desarrolla el evento. ¿Cómo podemos conocer si existe una respuesta por parte del receptor del estímulo que ha enviado el emisor? Existen dos formas de retroalimentación del sistema:

- la primera de forma más directa, es decir, las personas que están presentes mientras se produce el acontecimiento y muestran una respuesta inmediata a través de los procesos de: participación, observación, compra, donación y obediencia.

- La segunda forma de feed-back es indirecta: las personas que se exponen a esas acciones de ambient marketing caracterizadas por la novedad y originalidad creativa son impresionados por las mismas. Estas personas a su vez cuentan la experiencia percibida a otras personas de su entorno. Este tipo de acciones generan el proceso comunicativo del "boca a boca". Este fenómeno provoca que la acción de ambient marketing, que en principio es un evento aislado, se convierta en un acontecimiento y éste por el número de personas a las que afecta (notoriedad y repercusión), pueda convertirse en un fenómeno objeto de interés para los medios de comunicación de masas.

\section{4.- Ambient Marketing: Para Captar La Atención}

Este tipo de publicidad se distingue por agrupar todas aquellas acciones dirigidas a llamar la atención ${ }^{11}$, generando rumores que vayan de boca en boca, de manera que el receptor del mensaje sea también emisor, (como hemos visto en la figura 3), y por

\footnotetext{
${ }^{11}$ Ver artículo aparecido en The Economist. http://www.economist.com/business/displayStory.cfm?Story_ID=393109
} 
lo tanto, evidenciando su mayor ventaja: unos costes mucho menores que un anuncio en un medio convencional como por ejemplo la televisión.

Hovland, Joanis y Kelley (1953) fueron los primeros en sugerir que el impacto persuasivo de una comunicación dependía de la activación de tres procesos sucesivos:

- Procesos de atención.

- Procesos de comprensión.

- Procesos e aceptación.

Según este planteamiento, para que los mensajes resulten eficaces es necesario que el receptor preste un mínimo de atención, a continuación lo comprenda y que lo capte en mayor $\mathrm{y} / \mathrm{o}$ menor grado.

Estos tres procesos están estrechamente relacionados con la novedad y originalidad creativa. Cuesta (2000:87) en este sentido comenta: "El efecto repetición del estímulo se encuentran íntimamente unido al de novedad del estímulo, aunque solo sea porque, obviamente, cuanto más se repite un estímulo menos novedoso resulta".

Vinokur y Bunstein (1978) introdujeron el concepto "novedad" del argumento como una característica relevante del proceso de comunicación persuasiva. En este sentido Cuesta $(2000: 87,88)$ indica que Wyner había ya demostrado que la información novedosa juega un papel fundamental en el proceso de formación de actitudes y que la producción de un discurso en el que aparecen elementos novedosos produce una impresión más fuerte que aquél en el que no parecen. 

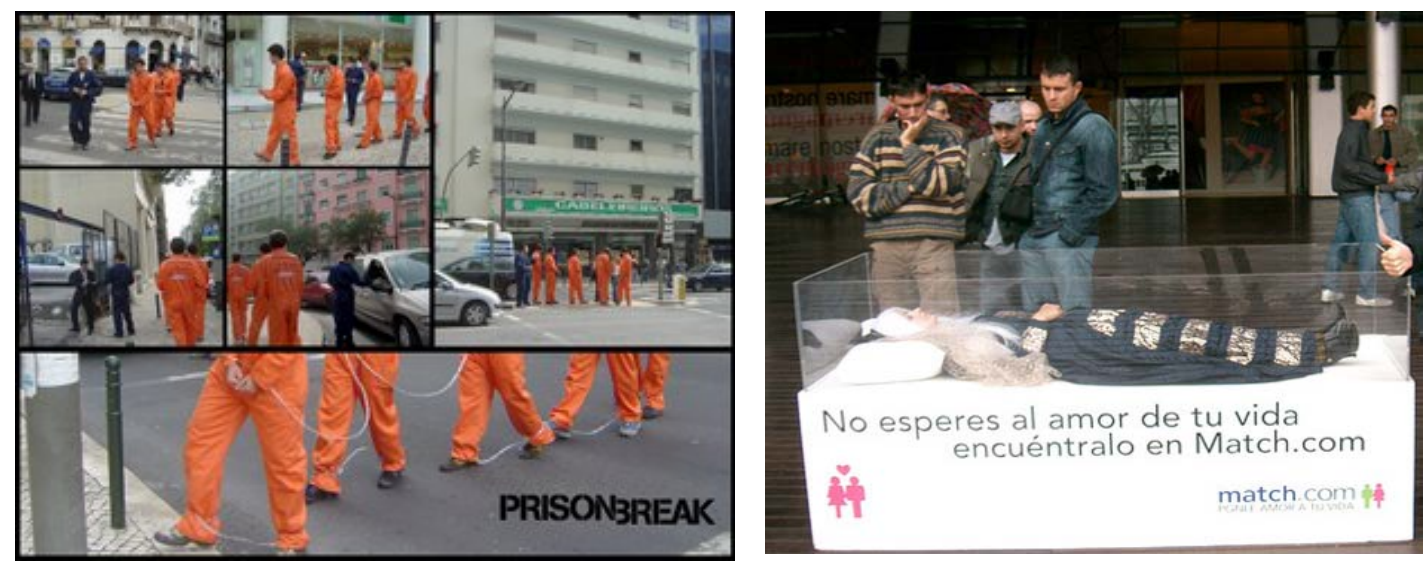

Figura 7 y 8: Acciones de ambient marketing realizadas para promocionar la serie PrisiónBreak y la agencia de encuentros Match

El concepto de novedad ha sido operativizado de dos formas:

- apelando al concepto de índice de redundancia, que hace referencia al número de veces que el argumento ha sido empleado en el discurso.

- apelando al estado de los conocimientos del receptor o audiencia; éste es un criterio subjetivo, de novedad percibida, el cuál hace referencia a la medida en la que el elemento forma parte del repertorio argumentativo del receptor.

Si el estímulo que emite el emisor transgrede en el marco de referencias aprendidas y adquiridas del receptor se activará un proceso de disonancia cognoscitiva. El contenido en este sentido es discrepante. La premisa más importante al aplicar este esquema a los procesos de persuasión social y comunicación, consiste en afirmar que a mayor contenido discrepante, mayor efecto de la comunicación, mayor aprendizaje, es decir, mayor cambio de actitud o persuasión, Cuesta (2008:81).

En este sentido hemos planteado un modelo teórico para explicar cómo las acciones de ambient marketing tienen un alto componente persuasivo. El emisor a través de este tipo de eventos (ambient marketing) envía un estímulo que tiene un protagonismo directo sobre el: cómo comunico el mensaje, sobre el canal o medio empleado y la situación o contexto en el que se desarrolla. Si ese estímulo es percibido por el receptor como novedoso, original, provocador, discrepante y 
seductor; provocará en el mismo una disonancia cognoscitiva, que se traducirá en una alta implicación y por ende; (como decía Cuesta) mayor aprendizaje, es decir mayor cambio de actitud o persuasión. Si por el contrario, el estímulo que recibe el receptor no es percibido como: novedoso, original, provocador, discrepante y seductor no provocará en el mismo un proceso de disonancia cognoscitiva.

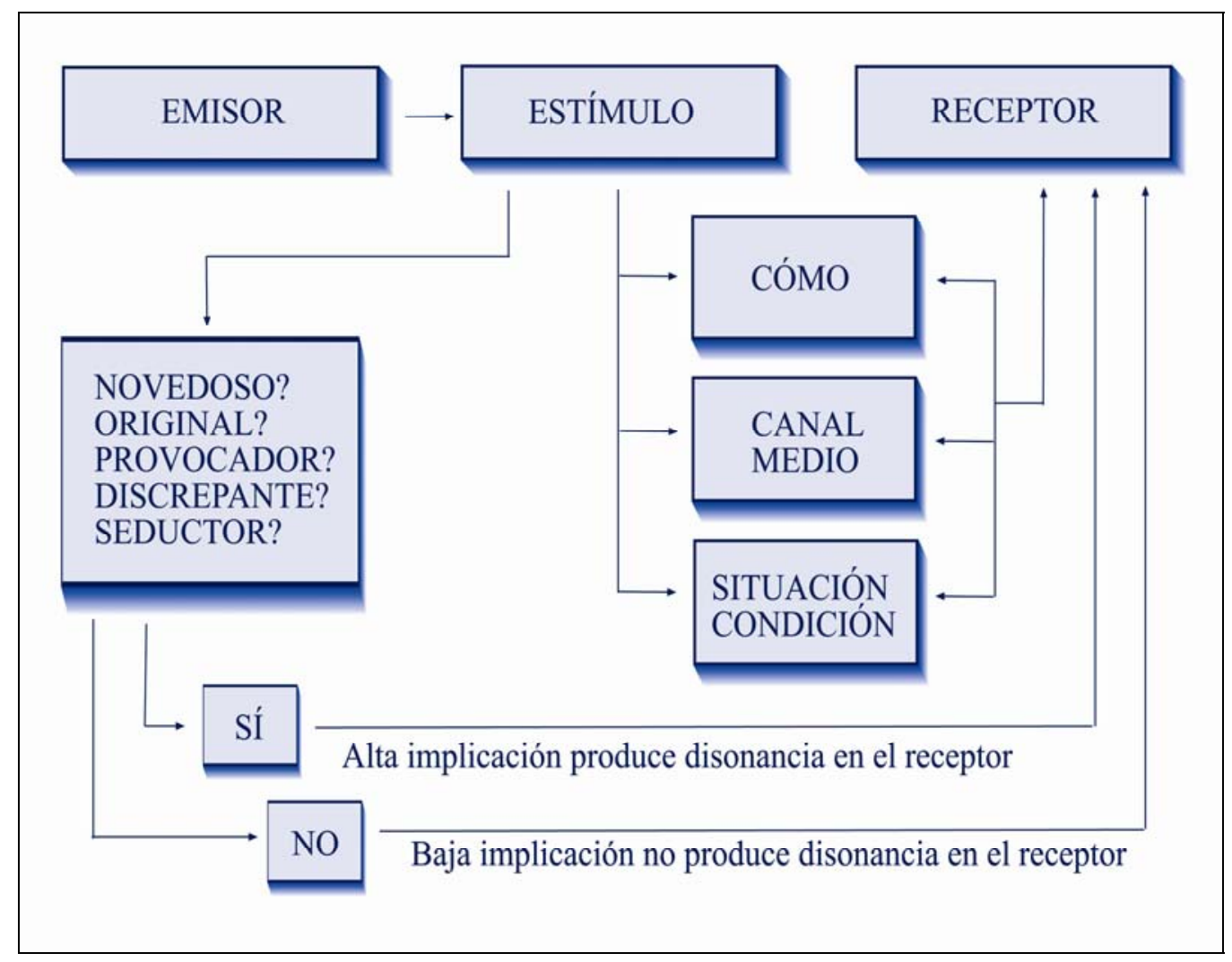

Figura 9: Modelo de procesamiento cognoscitivo de una acción de ambient marketing

\section{5.- Otros aspectos a considerar}

Estas acciones de ambient marketing están en fase incipiente en España ${ }^{12}$. Se llevan realizando hace algo más de un año. Como todas las tendencias publicitarias novedosas, éste tipo de acción presenta interrogantes que deberán ser contestadas en futuros trabajos de investigación. A saber:

\footnotetext{
${ }^{12}$ Mirar noticia del diario El País aparecida el día 10/09/2006 en la pág.44 y en última página del diario El País de $4 / 07 / 2007$
} 
- Hasta qué punto y en qué medida estas acciones cumplen los objetivos que la organización planteó a la hora de idear este tipo de acción.

- Como afecta este tipo de acciones a la marca y/o a la imagen, identidad y reputación corporativa de la empresa.

- A nivel jurídico no existen ninguna regulación normativa al respecto para este tipo de acciones ${ }^{13}$. Posiblemente si existiesen normas que regularan este tipo de actividad, se perderían los ingredientes esenciales del ambient marketing: novedad, atrevimiento, creatividad, originalidad y frescura.

- Si este tipo de acciones basan su poder de persuasión en la novedad y originalidad de la acción comunicativa puede perder eficacia si se copa el mercado de este tipo de acciones.

\section{6.- Conclusiones}

- El ambient marketing se configura como un nuevo medio de comunicación estratégica hacia el consumidor con una fuerte carga persuasiva. Supone para las marcas (organizaciones)una estrategia de diferenciación en sectores muy copados.

- El último fin de las acciones de ambient marketing es que no sean percibidas por el receptor como publicidad.

- La capacidad de persuasión de las acciones de ambient marketing reside en :

\footnotetext{
${ }^{13}$ A este respecto hicimos una consulta a los servicios jurídicos de Autocontrol (Organismo de Autorregulación Publicitaria). Nos indicaron que no existe ningún tipo de norma que regule el funcionamiento de este tipo de eventos y acciones publicitarias/relacionales.
} 
- La capacidad de generar sorpresa (novedad) en el receptor.Activa: la atención, la comprensión y la aceptación.

o No es percibido como una acción publicitaria por el ciudadano.

- La capacidad de relación con los públicos que entran en contacto directo con la marca.

- $\quad$ No existe un modelo que cuantifique la eficacia de este tipo de acciones.

Pero lo que nos debe quedar claro es que la comunicación no convencional, ha empezado a formar parte intrínseca de la comunicación de las marcas, como un fenómeno paralelo a la nueva relación con ellas, en la que la comunicación forma parte de la misma experiencia de la marca.

\section{7.- Bibliografía}

BAÑOS GONZÁLEZ, M. (2006): Creatividad y Publicidad. Madrid, Editorial Laberinto.

CABRERA, A. (2006): Qué estamos midiendo cuando medimos eficacia. Como abordar la medición de la comunicación no convencional. XI Seminario SEDEMO-aea: Eficacia de la comunicación Publicitaria. Barcelona 2 y 3 de Junio.

CUESTA CAMBRA, U. (2000): Psicología social de la comunicación. Madrid. Editorial. Cátedra.

De FLEUR, M. L. y BALL - ROKEACH, S. J. (1993): Teorías de la comunicación de masas, Barcelona, $2^{a}$ edición, Ed. Paidós.

HOVLAND, C.I., JANIS, I.L. and KELLEY, H.H. (1953): Communication and Persuasion. New Haven, Yale University Press. 
MARTÍN SERRANO, M. (2007): Teoría de la Comunicación. La comunicación, la vida y la sociedad. Madrid. Editorial McGrawHill.

MEDINAVEITIA, E. (2005): “Saturación y eficacia publiciatria” en Telos nº 64 Segunda época. Julio-Septiembre 2005. Madrid.

KOTLER. P. (2003): Fundamentos del marketing. México. Pearson Educación.

RODRÍGUEZ CENTENO, J. C. (2004): "La publicidad como herramienta de las distintas modalidades de comunicación persuasiva” en Global Media Journal n 1 Vol.1 Primavera de 2004.

SAN NICOLÁS ROMERA, C. (2003): Aspectos de comunicación y creatividad publicitarias. Murcia. Editorial Monografías de la Universidad Católica de Murcia.

WEST R. \& TURNER, L. H. (2005): Teoría de la Comunicación. Análisis y Aplicación. Madrid. McGrawHill. 